\title{
Environmental Impacts and Policy Options for Aviation: Taiwan's Responses within the Global Framework
}

\author{
Ho-Ching Lee ${ }^{1, *}$ and Wei-Chyung Wang ${ }^{2}$ \\ (Manuscript received 18 December 2000, in final form 22 February 2001)
}

\begin{abstract}
Aviation emissions of trace gases $\left(\mathrm{NO}_{\mathrm{x}}, \mathrm{CO}, \mathrm{H}_{2} \mathrm{O}\right.$, and $\mathrm{SO}_{2}$ ) and particles are believed to cause changes in the atmospheric $\mathrm{O}_{3}$ and climate with likely impact on the global environment. The anticipated large future increases in worldwide air traffic prompt a closer look by the international community of not only the environmental impact, but also the policy response to cope with the issue (IPCC 1999). This study presents the future changes in climate over East Asia in contrast with global change. An examination of the interplay between science and policy addressing international air transport is summarized and provides a reference for consideration of East Asia, in particular Taiwan. Given Taiwan's status in the international community and present domestic administrative structure, this paper suggests a set of policy options and recommendations within the context of a global policy framework.
\end{abstract}

(Key words: Aviation, Environmental impacts, Policy options)

\section{INTRODUCTION}

Atmospheric composition has changed since the industrial revolution mainly as a result of human activity (WMO 1999; IPCC 1996a, 2001). A large part of this change can be seen in the concentrations of carbon dioxide $\left(\mathrm{CO}_{2}\right)$ over the last century while other greenhouse gases, including methane $\left(\mathrm{CH}_{4}\right)$, nitrous oxide $\left(\mathrm{N}_{2} \mathrm{O}\right)$ and chlorofluorocarbons (CFCs) are also observed to be increasing in recent decades. On a worldwide scale, "global warming" associated with the enhanced "greenhouse effect" due to emissions of these gases is considered to pose one of the greatest threats to the Earth's climate and environment with profound impact on social and economic activities. In the last few years, a series of international activities orga-

\footnotetext{
${ }^{1}$ Center of General Education, Chung-Yuan Christian University, Chung-LI, Taiwan

${ }^{2}$ Atmospheric Sciences Research Center, State University of New York, at Albany, New York, USA

${ }^{\star}$ Corresponding author address: Prof. Ho-Ching Lee, Center of General Education, Chung-Yuan Christian University, Chung-Li, Taiwan, ROC; E-mail: hoching@cycu.edu.tw
} 
nized by the United Nations have been convened to address not only the climate and environmental impact [e.g., Intergovernmental Panel on Climate Change (IPCC)], but also the policy strategy for emission reduction [e.g., 1992 Framework Convention on Climate Change (FCCC), 1997 Kyoto Protocol, 2000 Hague and 2001 Shanghai meetings].

Recently, another major human activity of global scale is aviation. As summarized in the IPCC (1999) report, the effects of current aviation and of a range of unconstrained growth projects for aviation can influence the global environment with much larger effects on the flight routes over the North America, Europe, and East Asia. Two major environmental issues associated with aviation are recognized: aircraft noise and engine emissions. For noise, the International Civil Aviation Organization (ICAO) has set standards to tackle with noise pollution by reducing noise level at the source (ICAO 1982). Airplanes designed and built after October 1977 are under a set of noise standards issued by ICAO. While noise reduction at the source is the primary approach, other operational measures such as noise abatement take-off procedures, and proper planning of land use are also recommended.

As for aircraft engine emissions, increased international concern about their environmental impact has stimulated research efforts to access their impact. Specifically, an international environmental treaty (FCCC or Climate Convention) and its scientific advisory body, IPCC, is working together with ICAO to access the environmental impact of gas and particle emissions from aviation. In September 1996, the IPCC at the twelfth session adopted a special report on civil aviation, in collaboration with the Scientific Assessment Panel to the Montreal Protocol. The report of the IPCC (1999) signifies the first collaborative effort among the Climate Convention (dealing with climate change and global warming), Montreal Protocol (dealing with Ozone depletion) and ICAO (on international aviation standards and practices).

Several features are noted in IPCC (1999). Although IPCC has produced many scientific assessment reports on climate change, this is the first time IPCC has considered a specific industry sector. Secondly, it is a report of global scale, assessing potential past and future effects on $\mathrm{O}_{3}$ depletion and other global environmental changes. Regional and local environmental impacts are not covered and further studies are recommended. Thirdly, although this report contains "accurate, unbiased and policy-relevant information" to serve the aviation industry and the expert and policymaking communities, it does not propose any specific policy recommendations. The policy response to aviation emissions has to be developed by countries, individually or collectively.

Taiwan is located in the center of a major air traffic route over East Asia. The future traffic along this route is projected to increase at a faster pace than the routes over North America and Europe. Consequently, it is pertinent to consider both the environmental impact and policy considerations for this region. This paper discusses the contrasts in the aspects of global versus regional effects in both the environmental impacts and policy options, with special focus on Taiwan. In addition, it provides policy recommendations seeking to answer the question of why Taiwan should care about this issue and how it might effectively cope with the regional increase in aviation emissions. Given Taiwan's administrative structure as well as its international policy framework, a set of coping options and policy responses are discussed and recommended. 


\section{ENVIRONMENTAL IMPACT}

The importance of aircraft emissions to the climate and environment needs to be addressed within the context of other major climate changes such as global warming due to increasing atmospheric greenhouse gases $\mathrm{CO}_{2}, \mathrm{CH}_{4}, \mathrm{CFCs}$, and $\mathrm{N}_{2} \mathrm{O}$, and cooling due to sulfate aerosols (IPCC 2001). A common indicator for the comparison is "radiative forcing" which is a perturbation to the global- and annual-mean "radiation energy balance" of the Earthtroposphere climate system. Because of the strong dynamical coupling between the troposphere and surface, radiative forcing of the climate system is generally defined as the net solar and long-wave radiation flux at the tropopause, around $12 \mathrm{~km}$.

The principal emissions of aircraft include the greenhouse gases $\mathrm{CO}_{2}$ and water vapor; other major emissions are $\mathrm{NO}_{x}\left(\mathrm{NO}\right.$ and $\left.\mathrm{NO}_{2}\right), \mathrm{CO}, \mathrm{SO}_{2}$ and soot particles. The total amount of aviation fuel bumed and the associated total emission of these species are known (IPCC 1999) and the direct impacts of these emissions on the environment are being estimated. However, the uncertainty of the environmental impact is quite substantial, and to a large extent is related to the two indirect effects associated with these emissions: $\mathrm{NO}_{\mathrm{x}}$ induced $\mathrm{O}_{3}$ changes, and the formation of condensation trails (conrails) due to particles. The global aspects are discussed in Isaksen et al. (2001) while the characteristics over East Asia can be found in Chen et al. (2001) and Wang et al. (2001). Note that because of its long lifetime, the emitted $\mathrm{CO}_{2}$ attributed to aviation is not distinguishable from $\mathrm{CO}_{2}$ emissions from other sources. Likewise, it can affect the global climate with its magnitude of effect scalable to total $\mathrm{CO}_{2}$ emissions according to IPCC (2001) studies. On the other hand, the other emitted gases and particles have a shorter lifetime and remain concentrated near the flight routes.

We have conducted model assessment of the present and future effect on radiative forcing due to changes in the radiatively-important chemical species $\left(\mathrm{O}_{3}\right.$, water vapor and $\left.\mathrm{CH}_{4}\right)$ associated with aircraft emissions (Wang et al. 2000). The model simulations were run based on the University of Oslo (UiO) 3-D chemical transport models (CTMs) to calculate changes in atmospheric composition and the State University of New York at Albany (SUNYA) 3-D global climate model (GCM) to calculate the radiative forcing associated with these changes. Note that aircraft emitted $\mathrm{NO}_{x}$ participate in $\mathrm{O}_{3}$ chemistry with different effect at different altitudes. As discussed in Isaksen et al. (2001), $\mathrm{NO}_{\mathrm{x}}$ emissions from subsonic aircraft (flying in the $9-13 \mathrm{~km}$ altitudes) tend to increase $\mathrm{O}_{3}$ and decrease $\mathrm{CH}_{4}$, while emissions from supersonic aircraft (cruising at about $17-20 \mathrm{~km}$ ) decrease $\mathrm{O}_{3}$.

Here, we used these simulations to highlight the contrast in radiative forcing between the global and regional responses (in particular over East Asia). The year 2015 was chosen to illustrate the impact of future aircraft activity. Note that in the simulations, we used the IPCC IS92a scenario for the growth rates of the anthropogenic part of surface emissions of $\mathrm{NO}_{x}, \mathrm{CO}$, and NMHC. To assess the environmental impact, we conduct two cases, one for "subsonic only" aviation and the other for combined "subsonic and supersonic" aviation. For comparison purposes, the same amount of fuel is used in both cases and, for the combined aviation, $11 \%$ of the total fuel is consumed by supersonic aviation of 500 aircraft. Note that, because of the dry stratosphere, the supersonic aircraft flying at high altitudes can significantly increase the water vapor, with maximum increase between $10-20 \%$ at middle to high latitudes. In 
addition to water vapor increases in the stratosphere, $\mathrm{O}_{3}$ changes show an increase in the troposphere and decrease in the stratosphere with a strong latitudinal dependence.

As shown in Table 1, by the year 2015, the radiative forcing is calculated to be $0.036 \mathrm{~W}$ $\mathrm{m}^{-1}$ for subsonic aircraft, and $0.055 \mathrm{Wm}^{-2}$ for the combined subsonic and supersonic aircraft, which are 3.8 and $5.9 \%$, respectively, of the total radiative forcing caused by changes in $\mathrm{CO}_{2}$, $\mathrm{CH}_{4}, \mathrm{~N}_{2} \mathrm{O}$, and CFCs projected for the period. Note that the $\mathrm{CO}_{2}$ effect attributable to aircraft emission is included (about 3\%) in the $0.658 \mathrm{Wm}^{-2}$ forcing, and that decrease in the CFCs forcing is caused by the concentration decreases enforced by the Montreal protocol. Although the $\mathrm{O}_{3}$ effect on the global- and annual-mean radiative forcing is relatively small, the regional effect can be much larger, as illustrated in Fig. 1. The simulations show strong geographical and seasonal variations in the total radiative forcing, with peak values at the subtropics and mid-latitudes of the Northern Hemisphere attributed to the three major routes- North America, Europe and East Asia.

Table 1. Changes in globally averaged radiative forcing $\left(\mathrm{Wm}^{-2}\right)$ for the period 1992-2015 due to increases in $\mathrm{CO}_{2}, \mathrm{~N}_{2} \mathrm{O}, \mathrm{CH}_{4}$, and $\mathrm{O}_{3}$, decreases in CFCs, and aviation activity (Wang et al. 2000).

\begin{tabular}{|c|c|}
\hline Gases & $\mathbf{W m}^{-2}$ \\
\hline $\mathrm{CO}_{2}$ & 0.658 \\
\hline $\mathrm{N}_{2} \mathrm{O}$ & 0.056 \\
\hline $\mathrm{CFCs}_{\mathrm{CH}_{4}}$ & -0.022 \\
\hline $\mathrm{O}_{3}$ & 0.152 \\
\hline Total Greenhouse Gases & 0.092 \\
\hline Aviation: Case A & 0.936 \\
\hline Aviation: Case B & 0.036 \\
\hline
\end{tabular}

Case A: subsonic aircraft; Case B: combined subsonic and supersonic aircraft.

Note however that for East Asia, as indicated in Isaksen et al. (2001), the effect on radiative forcing due to aviation can be much larger because the growth rate in East Asia is underestimated in IPCC (1999). For example, in an emission inventory study by Lin et al. (2001), the amount of aircraft-produced $\mathrm{NO}_{\mathrm{x}}$ over Taiwan is about $69 \%$ of that produced in mainland China where the growth rate is already much larger than that used in IPCC (1999). Estimates in IPCC (1999) indicate that the radiative forcing by the middle of the $21^{\text {st }}$ century could be 5$15 \%$ of the total forcing, which would be significant. Consequently, Taiwan needs to closely watch development in the international arena with regard not only to the policy aspect, but also to the control strategy concerning aircraft emissions.

\section{POLICY ANALYSIS: GLOBAL PERSPECTIVE}

Environmental impacts derived from atmospheric research have been used to provide a foundation for policy inquiry. For example, the scientific findings from the IPCC have helped 

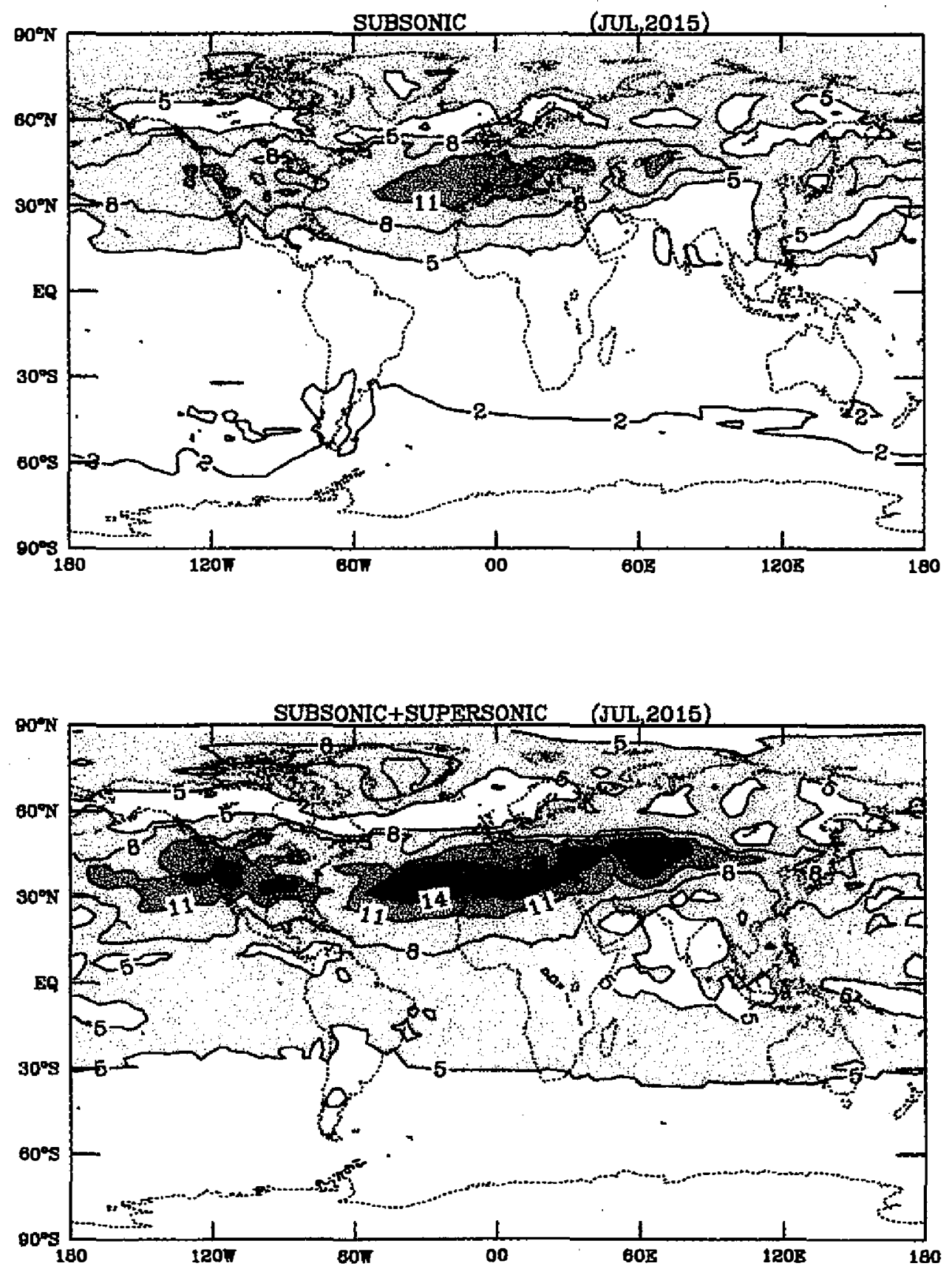

Fig. 1. SUNYA model simulated geographical distribution of July radiative forcing $\left(\mathrm{Wm}^{-2}\right)$ due to changes of ozone and water vapor caused by aviation emissions at 2015 for subsonic and combined subsonic and supersonic aviation (see Wang et al. 2000). 
to frame the issue of global warming, to initiate policy debates and to serve as a catalyst in forming the 1992 FCCC to reduce emissions of greenhouse gases. As the FCCC calls for the reduction of emissions from all sources, it naturally includes emissions from aviation. Taking a Convention-Protocol two-step approach (Susskind 1994), the FCCC gradually evolved into the more stringent Kyoto Protocol in 1997, and international aviation emission became an issue of greater concern. As a result, ICAO, through its Committee on Aviation Environmental Protection (CAEP) was recognized as the global instrument to pursue the reduction of greenhouse gas emissions from international aviation.

To facilitate the discussion of the policy analysis for the East Asia region (with focus on Taiwan) relevant to aviation emissions, this section briefly summarizes the framework of international treaties, their organization and functional dynamics, and coping options and mitigation strategies.

\subsection{International Framework}

As listed below, there are various international organizations, treaties and scientific advisory bodies involved in a concerted effort to assess and reduce aircraft engine emissions.

\section{International Civil Aviation Organization (ICAO)}

ICAO was established in 1944 as a United Nations specialized agency under the Convention on International Civil Aviation (known as the "Chicago Convention"). It serves as the focal organization responsible for formulating standards, practices, and guidance for the civil aviation industry. These standards and practices, generally viewed as binding and continuously being amended, are also taken into account in regulating domestic aviation by member states. More strict limits on aircraft emissions were adopted in March 1999, imposing a 16\% reduction in $\mathrm{NO}_{x}$ versus the 1993 limits. All new engines designed after 2003 will follow this new emission standard. All contracting states to ICAO, in principle, are in compliance with these standards. In cases of non-compliance, contracting states are required to notify the ICAO of any differences between their national regulations and practices and the international standards.

\section{Committee on Aviation Environmental Protection (CAEP)}

Within ICAO, CAEP is a technical committee with members made up of experts from seventeen ICAO contracting states and observers from non-governmental organizations (NGOs), industry associations, the World Meteorological Organization (WMO) and the Secretariat of the FCCC. Working closely with national authorities, CAEP reviews aircraft certification processes and proposes changes in recommended environmental standards on noise and emissions.

In the 1990s, in particular FCCC in 1992 and Kyoto Protocol in 1997 were gradually evolved, ICAO was called upon to engage in a collective effort to curb emissions of greenhouse gases. Two areas of expertise of special interest to FCCC are the methodology used for producing greenhouse gas inventories and the allocation of emissions from international aviation. The specific provision and terminology used in the Kyoto Protocol is referred to as "aviation bun- 
ker fuels." Emissions from domestic flights are part of the national inventory. However, the most difficult problem in compiling greenhouse inventory is how to allocate emissions from these international flights. At the present time, CAEP has developed different allocation options - based on the country of departure or destination, the country where the aircraft is registered, the country where the fuel is sold, or a proportional allocation to global bunker sales. Nevertheless, international aviation emissions are currently not included in national inventories and, consequently, not counted in the emission reduction targets. As the Kyoto Protocol stands, the issue of international aviation allocation is not yet fully resolved and all these allocation options will be further discussed in the following sections on IPCC and FCCC.

\section{IPCC and FCCC}

In 1988, WMO and the United Nations Environmental Programme (UNEP) jointly established IPCC and stated that the role of science exists in the case of climate change and global warming (Haas 1992; Bolin 1994; Watson 2000). Working Group-I of IPCC has been the most active and visible, producing 1990, 1992 and 1995 (IPCC 1996a) reports on scientific assessment with the newest report scheduled for completion in 2001. The importance of these scientific assessment reports to the policy debates cannot be neglected. Throughout this science/policy evolution process, it was the 1990 assessmentreport that led to the FCCC. Further, it was the 1995 report that led to the Kyoto Protocol at the $3^{\text {rd }}$ Conference of the Parties (COP 3). In November 1998 in Buenos Aires when the COP 4 was held, there was a recommendation made by many nations to link further reviews of the adequacy of commitments to the scientific assessment cycle of the IPCC. The 1999 special report on "Aviation and the Global Atmosphere" is the first time that IPCC considered a particular industry sector.

\subsection{Potential Mitigation Measures}

Essentially, three kinds of measures are generally considered: technology options, operational measures, and market-based options. The following section describes how these mitigation measures may reduce aviation emissions and what are the criteria used to make public and industry decisions.

\section{Technology Options}

Civil aviation is a technology-intensive industry. Airplanes are products of high technology, and the aviation industry drives technology to advance further. Two potential options are being considered: engine technology and fuel option. In the past 40 years, airplane fuel efficiency has greatly improved by $70 \%$ through improvement in design and engine advancement. In fact, more than half of this improvement comes from one single factor: engine improvement. Up till now, the most fuel-efficient engines were the high-bypass, high-pressure ratio gas turbine engines. Potentials for further technological advances still remain, mostly in aerodynamic efficiency, new materials and better control and handling systems.

In terms of efficiency, fuel can also be improved to be more efficient. Subsonic airplanes are now about $70 \%$ more fuel efficient than forty years ago. Based on recent research (IPCC 
1999), a $20 \%$ improvement in fuel efficiency is projected by 2015 and a further $40 \%$ to $50 \%$ improvement by 2050 as compared to airplanes produced now.

Currently, aircraft fuels used are kerosene-type fuels. An alternative fuel, hydrogen, has also been proposed, as it would eliminate $\mathrm{CO}_{2}$ emissions and largely reduce $\mathrm{NO}_{\mathrm{x}}$ from aircraft. However, the use of hydrogen as an alternative would create major design problems. Other potential changes may involve global change in supply, ground handling and ground storage. While the use of hydrogen is still debatable at this time, the primary option for the next 50 years will continue to be kerosene-type fuels.

In addition to fuel efficiency and fuel type, advances in combustor technology may result in emission reductions of $\mathrm{NO}_{x}$. For instance, engines with higher-pressure ratios would better meet more strict emission standards for $\mathrm{NO}_{\mathrm{x}}$. As the current regulation on $\mathrm{NO}_{\mathrm{x}}$ standards is based on landing/take-off (LTO) cycles, emission standards at cruise altitudes are not properly addressed. ICAO is therefore considering the development of a new emission parameter to cover climb and cruise emissions. Cruising at higher altitudes, emissions of supersonic aircrafts present another problem. The ICAO has therefore begun considering the development of specific emissions standards for next generation of airplanes.

\section{Operational Measures}

The conventional approach to air traffic management (ATM) usually has three elements: air traffic control, air traffic flow management and air space management. As a primary ATM element, air traffic control serves more directly to collision prevention. Nevertheless, research work (FAA 1998 and ICAO 1998a) shows that improvements to ATM could reduce fuel burn per trip by 6 to $12 \%$.

A newer management approach combines ATM with CNS (Communication, Navigation and Surveillance) into a global and more integrated management system. CNS/ATN systems bring benefits to air transportation by reducing delays, increasing the capacity of the existing infrastructure and enhancing operational efficiency. Altogether, this new management system results in fuel savings, and in turn, reduces engine emissions.

To further save fuel and reduce emissions, there are several strategies to be considered: optimizing aircraft speed, reducing additional aircraft weight, increasing the load factor, reducing the use of auxiliary power units and reducing taxiing. The potential reduction in fuel burn by implementation of these operational measures is 2 to $6 \%$. Given a specific air raffic demand, the engine emissions will further be reduced accordingly.

All CNS/ATM measures are tied to the modernization of the air traffic system. Through efforts to modernize, it offers potential for reduced fuel consumption, safety, and environmental benefits. It is generally concluded that potential gains from measures within the current air traffic system are much smaller than those that may be gained through modernization of the air traffic system. However, modernizing the air traffic system is primarily the responsibility of 
each country. A successful, full and timely implementation of CNS/ATM would require national commitment and international collaboration.

\section{Market-based Options}

The focus of aviation policy has been on command and control; that is, government control and regulation from the top. The emphasis has now changed to efficiency and quick response to changing demand. This newer trend, in fact, represents an integrated process, combining deregulation and market mechanisms.

IPCC (1996b), ICAO (1998b) and a few other studies have investigated market-based or economic measures for mitigating aviation emissions. They have recommended:

- fuel taxes and charges to increase fuel efficiency

- emission charges to encourage the development of lower emitting technology

- emission trading through market mechanism

- charges on empty aircraft seats to improve load

- charges on excessive traffic per destination and on route length to reduce the number of flights that are less than a minimum distance

- using subsidies as incentives

Generally categorized, there are basically four kinds of charges: a fuel charge, a ticket charge, a route charge and an airport charge. It has been discussed that route or fuel charges would be the most effective and airport charges would be most effective in reducing local emissions. Having said this, at the present time, most of these options are still in a conceptual phase and the practical problems need to be further addressed and worked out. There is also a difference of views (for instance, on route charges and on emission trading among the developed and developing countries) at this time and no consensus has been reached.

More recently, through the development of aircraft certification standards, aircraft noise and engine emissions can be largely reduced. Airline companies, in return, have begun to address environmental issues. Some make careful decisions in their choice to operate fleets that pollute less and some incorporate environmental policy and measures into their performance goals. All in all, there is a general agreement reached within CAEP that all mitigation options have to be based on "environmental need, technical feasibility and economic reasonableness. "These criteria are now largely used for making environmentally friendly investment decisions.

\section{POLICY ANALYSIS: TAIWAN PERSPECTIVE}

After reviewing the international policy framework on aviation and the global atmosphere, we now tum our attention to the regional approach and considerations. Here, global versus regional and especially Taiwan's policy options will be discussed and highlighted in the realm of the global mitigation strategy of technology, operational/management, and market-based options. 


\subsection{Administrative Structure}

In Taiwan, the standards for noise control and aviation emissions set by ICAO are issued by the Civil Aeronautics Administration (CAA), Ministry of Transportation and Communications. Within CAA (1999), there are seven divisions (planning legal and international affairs, air transport, flight standards, air traffic services, aerodrome engineering, air navigation facilities and logistics divisions), five offices (information, administration, accounting, personnel and government ethics), three international airport offices (Chiang KaiShiek, Taipei and Kaoshiung) and fourteen domestic airport offices. The division of air traffic services undertook the environment-related activities and the major function was only noise control.

Starting in July 2000, a new section on "environmental protection" has been established under the division of aerodrome engineering. It is the first time that the concept of environment protection has been "institutionalized" into a section under the existing administrative framework. In addition, there was a switch of divisions from "air traffic services" to "aerodrome engineering" as it relates more to the engineering aspects of environmental protection. The establishment of this new section is a result of the Civil Aviation Act of article 35 for noise control while aviation emissions are a relatively new agenda.

Taiwan is no exception to the global trend of civil aviation. However, aviation in Taiwan for a long time was mostly a government protected industry where China Airlines was the only national carrier. As it now stands, the industry has been fully deregulated. For instance, Eva Airways, Mandarin Airlines, and Far Eastern air transport have launched international scheduled services. In 1998, Taiwan carriers handled about 17 million international passengers. A steady and rapid growth is expected for the future. Furthermore, deregulation allows for active competition in market entry and exit, airline fares, and capacity growth. It also initiates more bi-lateral air service agreements to make international aviation a really open sky for fair competition.

Perhaps the open sky is not so open when it applies to ICAO activities. For ICAO recommended technology approach, adherence to ICAO regulation is the primary concern of CAA. All newly bought airplanes in Taiwan, under the guidelines set by ICAO, are certainly in compliance with emission standards. However, more attention has to be paid to the maintenance of existing airplanes. An aircraft usually lasts for 25 to 35 years. With this life expectancy in mind, any new purchase or potential engine changes will have to consider operational safety, environmental and cost factors. How to strike a balance between environmental protection and cost efficiency remains a policy issue to be tackled with careful and difficult decisions to be made.

In terms of operational approach, again, Taiwan adopts a CNS/ATM management system as specified by ICAO. Basically, "doing by the ICAO books" is the theme underlying Taiwan's civil aviation management system. Implementation of these operational measures is an adminis ative challenge. However, a greater challenge lies in the lack of direct communication with ICAO, the lack of presence in ICAO related meetings and conferences, and the lack of participation in ICAO sponsored academic workshops. 


\subsection{Policy Response}

As discussed in the section of environmental impact, a snapshot of the scenario now suggests that the radiative forcing of current aviation emissions is about $3-5 \%$ of that due to increases in total greenhouse gases. By the year 2050, however, this percentage may be going up to 5-15\% (IPCC 1999, 2001). Note that a significant portion of this increase can be attributed to the projected increase of air traffic over the East Asia region (Airbus 1997; Boeing 1999). These together with the on-going international forum discussing policy options highlight the importance of addressing policy response for Taiwan. Considering the various aspects of Taiwan's situation discussed in Section 3, a list of recommendations and actions for implementation are presented below.

\section{Research and Development}

There is no other basis for sound policy decisions than the best available scientific evidence. This is especially true in the fields of resource management and environmental protection. According to Gro Harlem Brundtland, former Prime Minister of Norway and the author of the milestone report entitled "Our Common Future," science must underpin our policies. "If we compromise on scientific facts and evidence, repairing nature will be enormously costly - if possible at all" (Brundtland 1997).

This is also the case with aviation emissions. Global research efforts had just begun in 1999 when the IPCC special report was published. It is timely to initiate relevant studies on a regional basis and begin to address aviation related policy issues. For example, CAA can provide seed money for start up projects. The National Science Council, the national scientific funding agency, may then incorporate this research topic into its research agenda in the near future. Eventually, a partnership among funding agencies such as the Central Weather Bureau, Environmental Protection Administration, National Science Council, and CAA should be formed to launch a more comprehensive research project by cross-university, cross-discipline research teams.

The potential research topics may include the following: present and future emission inventory; policy exercise incorporating the various international scenarios; monitoring climate and environmental parameters for detection of changes; and analysis and modeling efforts to address the physical and chemical formation and dissipation of particles to form contrails and cirrus clouds.

\section{Legal Framework}

The Noise Control Act was amended in 1994 to incorporate airport-related noise control into the official legal framework. While this legal framework exists to take care of noise control (compliance with ICAO noise standards, inspection and monitoring noise level, zoning, compensation schedules, coordination between the Environmental Protection Administration and CAA, and local government involvement), a similar legal framework needs to be established to set standards and monitor compliance for emissions. Relevant administrative orders and 
operational guidelines, especially for older aircraft, are worthy of consideration.

\section{Administrative Setting}

It is suggested that the CAA expand its function to include the existing division of aircraft emissions affairs. Under the current CAA's organizational chart, the environmental protection section of the aerodrome engineering division is in charge of aircraft noise affairs. It is logical that this division addresses this other environmental concern. At present their function is dealing with control of emissions rather than taking preventive measures. In the future, it is recommended that this section be expanded to take a more comprehensive approach rather than an engineering approach.

\section{International Collaboration}

It is critical that Taiwan's participation in ICAO meetings and related activities is increased to keep informed of new developments. Since Taiwan is not an ICAO member, we need to develop a strategy to participate as a NGO (non-governmental organization). This strategy should include representatives from government, industry, academia and NGOs. At present, we take part in all relevant FCCC meetings under the name of ITRI (Industrial Technology Research Institute). A similar approach can be adopted for ICAO functions.

\section{Institutional Arrangement}

Presently, the National Council for Sustainable Development (NCSD) of the Executive Yuan coordinates all the environmental affairs among different ministries. The NCSD has set up eleven working groups on issues associated with international sustainable development and environmental protection. More specifically, out of the existing eleven working groups, a task force on atmospheric protection and energy deals mainly with FCCC (reduction of greenhouse emissions) and Montreal Protocol (phase out the use/production of ozone depleting substances). The scope of "atmospheric protection and energy" seems to involve mostly energy production, conversion and consumption. It is recommended that the activity of NCSD be expanded to include aviation emissions to provide a public forum for policy development. The convening agency of this task force is suggested to be a joint effort between the Environmental Protection Administration and Ministry of Transportation and Communications.

\section{CONCLUDING REMARKS}

At first glance, the magnitude of the present-day effect attributable to aircraft emission, 3$5 \%$ of the global warming caused by increase of greenhouse gases, seems only marginally important. However, if the trend of aviation emissions continues, the "business-as-usual" scenario would pose a much greater impact, up to $5-15 \%$ by the middle of the $21^{\text {st }}$ century, as East Asia is the fastest growing region of air transport. As reported in the IPCC (1999), the potentially increasing impact on global climate and environment due to aircraft emissions 
have prompted the study of the policy response and control strategy to curb the emissions. Here, we presented a study of the implications of these global changes for Taiwan in these aspects and suggested actions to follow-up on on-going international activities, including research and development, legal framework, institutional development and international cooperation.

At its core, this paper is a precautionary policy roadmap, providing a framework of coping options and mitigation measures. It helps us understand how aviation emissions impact global atmosphere and how the international community copes with and responds to them. It examines the major actors, institutions, and state-of-the-art science shaping policy recommendations. It calls for action to be taken in the field of research, international collaboration via NGO channels, an upgraded and integrated administrative setting and the establishment of a legal framework and institutional arrangement. This paper is only a first step in a long process, a framework for action, and a work to initiate progress.

Acknowledgements The authors wish to thank Ming-Hung Hsu, section chief, Division of Aerodrome Engineering, CAA for providing institutional information. This research is supported by grants from the National Science Council, NSC-892621-Z-033-002.

\section{REFERENCES}

Airbus, 1997: Global Market Forecast 1997-2016, Toulouse, France.

Boeing, 1999: Annual Report - Exciting Opportunities, Seattle, Washington, USA.

Bolin, B., 1994: "Science and Policy Making". AMBIO, 23, 25-29.

Brundtland, G. H., 1997: “The Scientific Underpinning of Policy." Science, 177, 457.

CAA, 1999: An Introduction to the Civil Aeronautics Administration, MOTC, ROC.

Chen, J.-P., W.-H. Lin, and R.-F. Lin, 2001: Estimation of Conirail Frequency and Radiative Effects over the Taiwan Area. TAO, 12, 155-178.

FAA, 1998: Impact of CNS/ATM Improvements on Aviation Emissions, information paper presented by the U.S. at the Worldwide CNS/ATM Systems Implementation Conference, Rio, Brazil, 11-15 May, 1998.

Haas, P., 1992: Introduction: Epistemic Communities and International Policy Coordination, (Ed.), International Organization, 46, 1-35.

ICAO, 1982: International Standards and Recommended Practices, Annex 16 Environmental Protection, Volume I - Aircraft Noise and Volume II - Aircraft Engine Emissions, 18/ $2 / 1982$.

ICAO, 1998a: Costs and Benefits for Providers and Users, information paper presented by ICAO at the Worldwide CNS/ATM Systems Implementation Conference, Rio, Brazil, 11-15 May, 1998.

ICAO, 1998b: Report of the Committee on Aviation Environmental Protection, working group 4, Fourth Meeting, Montreal, Canada, 6-8 April 1998, Document no. 9720.

IPCC, 1996a: Climate Change 1995: The Science of Climate Change. In: J. T. Houghton, L. G. Meira Filho, B. A. Callander, N. Harris, A. Kattenberg, and K. Maskell (Eds.), 
Cambridge University Press, Cambridge, UK.

IPCC, 1996b: Technologies, Policies, and Measures for Mitigating Climate Change: IPCC Technical Paper 1, IPCC working group II.

IPCC, 1999: Aviation and the Global Atmosphere. In: J. E. Penner, D. H. Lister, D. J. Griggs, D. J. Dokken, and M. McFarland (Eds.), Cambridge University Press, UK.

IPCC, 2001: Climate Change 2000: The Third Assessment Report. Cambridge University Press, Cambridge, UK. (In press)

Isaksen, I. S. A., T. K. Berntsen, and W.-C. Wang, 2001: $\mathrm{NO}_{x}$ emissions from aircraft: Its impact on the global distribution of $\mathrm{CH}_{4}$ and $\mathrm{O}_{3}$ and on the radiative forcing. TAO, 12, 61-78.

Lin, P.-H., W.-S. Sun, and J.-P. Chen, 2001: Emissions inventory of civil aircraft over Taiwan. TAO, 12, 39-60.

Susskind, L. E., 1994: Environmental Diplomacy: Negotiating More Effective Global Agreements, Oxford University Press.

Wang, W.-C., I. S. A. Isaksen, J. Wang, M. Gauss, and X.-Z. Liang, 2000: Atmospheric ozone as a climate gas: Studies concerning aircraft emissions. 105-119, in "Chemistry and Radiation Changes in the Ozone Layer." In: C. S. Zerofos, I. S. A. Isaksen, and I. Ziomas (Eds.), NATO Science Series C: Mathematical and Physical Sciences, Vol. 557, Kluwer Academic Publishers, Dordrecht/Boston/London.

Wang, W.-C., W. Gong, and J.-P. Chen, 2001: SUNYA regional model simulation of radiative forcing and its climate implication due to contrails over regions around Taiwan. TAO, 12, 179-194.

Watson, R. T., 2000: Report to the Sixth Conference of the Parties of the UNFCCC, online at http: www.ipcc.ch/press/sp-cop6-2.htm

WMO, 1999: Scientific Assessment of Ozone Depletion: 1998. Global Ozone Research and Monitoring Project, Report No. 44, World Meteorological Organization. 